\title{
O Sistema Municipal de Ensino em análise: avanços e desafios ${ }^{1}$
}

Sueli Menezes Pereira ${ }^{a}$

\section{Resumo}

Buscando verificar a existência de Sistemas Municipais de Ensino legalmente instituídos nos municípios da Região Central do Rio Grande do Sul(RS) este texto vale-se de pesquisa teórico-bibliográfica e documental, tendo como referência dados adquiridos através do projeto de pesquisa "Sistema Municipal de Ensino e Conselho Municipal de Educação: realidade e viabilidades", desde 2014. Busca contribuir para o avanço em relação às metas e aos compromissos do Plano Nacional de Educação (PNE/2014/2024), identificando fraquezas e possibilidades. Aborda a organização do Sistema Municipal de Ensino e, neste, a importância da Secretaria Municipal de Educação que, em conjunto com o Conselho Municipal de Educação e a rede escolar, formalizam o Sistema Municipal de Ensino. Os resultados indicam que a existência de legislação formalizando um Sistema Municipal de Ensino não é garantia de sua operacionalização na prática.

Palavras chave: Sistema Municipal de Ensino. Legislação municipal. Desafios.

\section{Introdução}

Este texto trata da organização e funcionamento do Sistema Municipal de Ensino. Para tanto, discute a descentralização do Estado, na qual o município, como poder local, assume relevante importância, considerando a estrutura políticoadministrativa posta pela Constituição Federal de 1988 (BRASIL, 1988) e pela Lei de Diretrizes e Bases da Educação Nacional (LDB, Lei no 9.394/1996) (BRASIL, 1996b) que, ao promover maior descentralização ao Estado brasileiro, outorgou novas competências e atribuições aos entes federados, o que não se constitui em uma benesse do capital, mas, ao contrário, em uma estratégia de sua própria sobrevivência.

\footnotetext{
Artigo resultado de projeto de pesquisa integrado ao Grupo de Estudos e Pesquisas em Políticas Públicas e Gestão Educacional (GEPPEG). Esta pesquisa não contou com financiamento.

a Universidade Federal de Santa Maria. Santa Maria, Rio Grande do Sul, Brasil.
} 
São as consequências dos novos tempos de economia globalizada, pela qual as contradições inerentes ao próprio sistema capitalista permitem que estruturas centralizadas percam espaço para decisões locais, colocando novos desafios para os cidadãos que, se compreendidas politicamente no contexto em que vivem, também possibilitam novos espaços a serem assumidos conscientemente pela sociedade.

Nesse cenário, formaliza-se o Sistema Municipal de Ensino (SME), permitindo aos municípios criar suas próprias regras de gestão educacional, o que consagra o poder local como locus de decisões significativas para a sociedade. Essa é uma grande inovação, considerando a autonomia do município para organizar, conforme as necessidades locais, uma rede de escolas mantidas e administradas pelo poder municipal, um órgão gestor, a Secretaria Municipal de Educação e um órgão normativo e fiscalizador - o Conselho Municipal de Educação. Essas instâncias de poder, criadas através de leis e normas próprias do sistema, consagram, assim, a autonomia municipal na área da educação (MONLEVADE, 1997) de modo a garantir, de acordo com o artigo 15 da LDB, que os sistemas de ensino assegurem "às unidades escolares públicas de educação básica que os integram, progressivos graus de autonomia pedagógica e administrativa e de gestão financeira, observada as normas gerais de direito financeiro público" (BRASIL, 1996b).

Nesse contexto, o Plano Nacional de Educação - PNE/2014/2024 - enfatiza a importância da criação de Sistemas Municipais de Ensino através de legislação própria "no prazo de 2 (dois) anos contados da publicação desta Lei, adequando, quando for o caso, a legislação local já adotada com essa finalidade" (PNE/2014, art. $9^{\circ}$ ) (BRASIL, 2014).

A condução de políticas municipais de educação para as instituições de ensino visa a buscar uma melhor qualidade para a educação municipal no sentido de "elevar a educação à categoria do maior problema político brasileiro, dar-lhe base técnica e científica, fazê-la encarnar os ideais da república e da democracia" (TAVARES, 1952, p. 10).

Cumpre observar que o município é a base, o ponto de partida para a construção de uma educação de qualidade social, para o que é necessário que o Sistema de Ensino estimule discussões locais sobre a função social da educação como promotora da construção de conhecimentos que subsidiem e sustentem ações voltadas para o desenvolvimento social e econômico. Para tanto é fundamental que a gestão municipal exerça uma ação política comprometida com a permanente construção da qualidade social da educação. É nesse panorama que se consolidam os Sistemas Municipais, pois é no município que a 
[...] produção material e simbólica, o acesso à renda, ao conhecimento e à tecnologia, os meios e as formas de comunicação e deslocamento denotam a existência de grupos sociais e de relações mais amplas e poderosas que o lugar e, consequentemente, de necessidades e interesses diversos (BRASIL, 2006, p. 13).

O município deve ser reconhecido pela escola e pela sociedade, tanto nos processos educativos formais, como nos não formais, o que pode contribuir para que vários setores da sociedade se movimentem em busca de formação e participação como atividades permanentes, expressão da política educacional do município. Fóruns de debates dos problemas municipais, conferências municipais de educação e planejamentos participativos são alguns exemplos de ações que, integradas a todos os setores da comunidade, favorecem a efetivação de Sistemas Municipais de Ensino.

A reflexão tem-se calcado nos avanços da compreensão desse processo, bem como dos gargalos e desafios que se colocam ao esforço em empreender um processo educacional comprometido com os princípios esboçados.

Para tanto, este texto vale-se de pesquisa bibliográfica e documental, tendo como referência os documentos e dados adquiridos através do projeto de pesquisa intitulado "Sistema Municipal de Ensino e Conselho Municipal de Educação: realidade e viabilidades" (PEREIRA, 2014), em andamento desde 2014 na Universidade Federal de Santa Maria/RS, o qual integra o Grupo de Estudos e Pesquisa sobre Políticas Públicas e Gestão Educacional (GEPPGE). Esta pesquisa objetiva verificar a existência de Sistemas Municipais de Educação legalmente instituídos nos municípios da Região dos Municípios do Centro do Estado do Rio Grande do Sul (Região A. M. Centro), constituída, atualmente, por 34 municípios.

Neste prisma, busca-se contribuir para o avanço, em relação às metas e aos compromissos do PNE/2014, o que permite identificar fraquezas e reais possibilidades.

Para o desenvolvimento dessas ideias, o texto trata, inicialmente, da organização do Sistema Municipal de Ensino e, neste, a importância da Secretaria Municipal de Educação (SMEC) que, em conjunto com o Conselho Municipal de Educação (CME) e a rede escolar, formaliza o SME. Após, analisa os dados coletados pelo projeto de pesquisa mencionado e, por fim, algumas considerações referentes ao estudo realizado. 


\section{O Sistema Municipal de Ensino}

Revendo a história, observa-se que, em 1925, Anísio Teixeira criou a Lei no ${ }^{\circ} .846$, para reformar a Instrução Pública do Estado da Bahia. Com essa lei, propunha-se a criação daquilo que seriam os primeiros Conselhos Municipais de Educação no país, de modo a estimular o desenvolvimento do ensino primário, fiscalizar o serviço escolar do município e propor medidas convenientes à melhor adaptação do ensino às condições locais (SANTOS, 2000).

Seguindo esses princípios democráticos, Teixeira foi elaborando, ao longo de suas atividades na vida pública, o que se pôde chamar de ideário pedagógico municipalista. Isto é o que afirma Azanha (1991) ao salientar que a tese e a luta pela municipalização do ensino primário são muito antigas no Brasil, e o marco nessa trajetória é o pensamento de Anísio Teixeira.

A CF/1988 sinaliza para a ideia de Sistema Municipal de Ensino, ao estabelecer em seu artigo 211 que "A União, os Estados, o Distrito Federal e os Municípios organizarão, em regime de colaboração, os seus sistemas de ensino". A LDB consolida a ideia de Sistema Municipal ao instituir, no artigo 11, que os municípios incumbir-se-ão de:

I - organizar, manter e desenvolver os órgãos e instituições oficiais dos seus sistemas de ensino, integrando-os às políticas e planos educacionais da União e dos Estados;

III - baixar normas complementares para o seu sistema de ensino;

IV - autorizar, credenciar e supervisionar os estabelecimentos do seu sistema de ensino (BRASIL, 1996b).

Para o atendimento do ensino fundamental, com prioridade, os municípios deveriam contar com recursos financeiros para o que se instituiu em 1997 o Fundo de Manutenção e Desenvolvimento do Ensino Fundamental e de Valorização do Magistério (Fundef) $)^{2}$, como um fator indutor do processo de municipalização do Ensino Fundamental. De acordo com a legislação, o fundo "será distribuído entre cada Estado e seus Municípios, proporcionalmente ao número de alunos das respectivas redes de ensino fundamental" (MOTA, 2007, s/p). Dez anos

\footnotetext{
2 O fundo foi instituído pela Emenda Constitucional n. 14, de setembro de 1996, e regulamentado pela Lei $n^{\circ} 9.424$, de 24 de dezembro do mesmo ano, e pelo Decreto $n^{\circ} 2.264$, de junho de 1997 . Foi implantado, nacionalmente, em $1^{\circ}$ de janeiro de 1998 , quando passou a vigorar a nova sistemática de redistribuição dos recursos destinados ao Ensino Fundamental (BRASIL, 1996a).
} 
depois, este fundo foi substituído pelo FUNDEB, através da Lei no 11.494/2007, ampliando o financiamento para toda a Educação Básica e suas modalidades.

Nesta ótica, os municípios ganham força e passam a conviver com a ampliação dos espaços e atuações democráticas, embora, como diz Arosa (2010, p. 77), "ainda tenham de lidar com ações clientelistas, assistencialistas e com interesses localizados". Neste cenário há uma relação de confronto entre concepções e ideais relativos às políticas públicas com variadas intervenções na confluência entre o global e o local.

O Sistema Municipal de Ensino se identifica no processo de descentralização, a qual, como modelo político-administrativo, é concebida como a redistribuição de poder entre instâncias governamentais, entre poderes estatais, entre o Estado e a sociedade - redistribuição de competências, de recursos, de encargos originários dos organismos centrais, implicando em uma redivisão do trabalho entre diferentes instâncias do sistema.

Neste cenário, o Estado Nacional deve "ceder lugar a autoridades regionais ou locais" (GÓMEZ, 2000, p. 20) como verdadeiros pontos de apoio das redes tecidas pelas grandes corporações transnacionais. Salientam-se, no entanto, as contradições deste modelo, visto que, se, por um lado, há o enfraquecimento dos Estados Nacionais, por outro, o próprio modelo econômico-liberal, fundado num modelo individualista, privatista e anti-Estado, requer um Estado forte para introduzir "pelo alto" as reformas pró-mercado na sociedade.

Assim se afirma a importância de Sistemas Municipais de Ensino no processo de descentralização, estabelecendo uma relação entre o global e o local, de modo a transferir as responsabilidades sociais do Estado para a sociedade, instituindo uma nova relação entre Estado e sociedade.

A ideia de Sistema de Educação no Brasil tem sofrido críticas, pois "Tal pressuposto se assentava na constatação de que a tônica das críticas à educação brasileira, formuladas inclusive e de modo especial pelos próprios educadores, estava na importação e na improvisação" (SAVIANI, 1983, p. 2), indicando a falta de planejamento, ou soluções transplantadas, o que enfraquece as esperanças colocadas na educação. Isso tornou o sistema frágil, sinalizando para a sua inexistência.

Para Saviani (1983), a educação é encontrada em todas as sociedades: as pessoas se comunicam tendo em vista objetivos que não o de educar e, no entanto, educam e se educam. Trata-se, neste caso, de educação assistemática que ocorre em nível da consciência espontânea. 
O homem é capaz de educar de modo sistematizado quando toma consciência da educação e da situação educacional; capta seus problemas; reflete sobre eles; formula-os em termos de objetivos realizáveis; organiza meios para alcançar os objetivos; instaura um processo concreto que os realize, como aponta o autor: "O ato de sistematizar pressupõe a consciência refletida, o que indica ser um ato intencional. [...] Sistematizar, portanto, é dar, intencionalmente, unidade à multiplicidade, cujo resultado se chama sistema" (SAVIANI, 1983, p. 72, grifo do autor).

Entende-se, portanto, que sistema é a unidade de vários elementos intencionalmente reunidos, de modo a formar um conjunto coerente e operante, visto que, se o sistema nasce da tomada de consciência da problematicidade de uma situação dada, ele surge como forma de superação dos problemas que o engendraram, devendo, para ser sistema, contribuir para essa superação. Do contrário, terá sido ineficaz e, nesse caso, não terá sido um sistema, indicando que não pode haver sistema educacional sem educação sistematizada.

Tomar consciência dos problemas da realidade; formular uma teoria educacional, a qual deverá indicar os objetivos e meios que tornem possível a atividade comum intencional é a perspectiva em que se calca a ideia de formalização de sistema aberto e flexível, a partir de planos, projetos e ações das Secretarias de Educação, pois, quando educar passa a ser objeto explícito da atenção, desenvolve-se, aí, a educação sistematizada.

Ao analisar a teoria dos sistemas, Sander (1985), afirma que os cientistas consideram que a filosofia marxista-leninista "formula uma série de princípios metodológicos muito importantes para a análise de sistemas" (p. 9).

[...] o conceito básico da teoria dos sistemas é o de totalidade ou globalidade, conceito que surgiu como categoria lógica na doutrina de Hegel e firmou-se como categoria analítica entre sociólogos europeus, particularmente neomarxistas para, finalmente, operacionalizar-se nos Estados Unidos da América através de diferentes enfoques metodológicos (SANDER, 1985, p. 9, grifos nossos).

O sistema ultrapassa a educação individual, o que requer trabalho coletivo, ações democráticas na concretização dos objetivos da educação, sendo, portanto, o resultado intencional de uma ação intencional de grupo, o que leva à necessidade da teoria educacional, condição necessária para a existência do sistema. Isto será possível com reflexão radical, rigorosa e em conjunto, o que permitirá passar da consciência comum à consciência filosófica da práxis (SAVIANI, 1983), levando em conta que, para 
gerir o sistema educacional em busca de seu objetivo, a gestão educacional deverá conhecer os elementos que o integram, as atividades desses elementos e as relações entre essas atividades. Para tanto, "é preciso atuar de modo sistematizado no sistema educacional para que ele se constitua como sistema; do contrário irá degenerar-se em 'estrutura'. O burocratismo é um fator para isto" (SAVIANI, 1983, p. 36).

Nesse sentido, importa o modelo de administração dos sistemas, pois como lembra Sander (1985), a primeira grande tese foi exposta pela escola clássica de administração, englobando os movimentos científicos, geral e burocrático que se desenvolveram a partir do início do século XX.

A escola clássica concebe a administração como um sistema fechado, em que a administração está preocupada com o processo interno, a mecânica racional, a engenharia humana, a eficiência e a produtividade. Seus modelos são racionais, processuais e taxonômicos, com todas as limitações inerentes ao mecanicismo fisicista e à lógica positivista que caracterizaram as ciências no princípio do século. Basta examinar a obra de Taylor, Fayol, Weber, Gulick, Urwick para citar apenas alguns os principais protagonistas da escola clássica de administração (SANDER, 1985, p. 23-24, grifos nossos).

Da escola clássica de administração, salienta-se o taylorismo em nossas organizações escolares. Fruto da ética protestante, das práticas de engenharia mecânica e do racionalismo econômico da Revolução Industrial, o taylorismo enfatiza o planejamento, a mecanização, a estandartização, a racionalização e a produtividade, o que não condiz com perspectivas democráticas de gestão da educação. Em resumo, a "administração clássica com seus movimentos científico, geral e burocrático, adota um modelo mecânico concebido para analisar e dirigir sistemas fechados" (SANDER, 1985, p. 24).

Após a II Guerra Mundial, no entanto, como explica Sander (1985), "a escola contemporânea de administração [...] considera a organização como um sistema aberto em que a administração está chamada a desempenhar um papel mediador entre o indivíduo, a organização e a sociedade" (p. 26), evidenciando que a administração é elemento central para o funcionamento de qualquer sistema.

Um sistema fechado apresenta limites impenetráveis ao próprio sistema, não possibilitando nenhuma alteração ao mesmo. No sistema aberto, existe um movimento de entrada e saída de elementos através das fronteiras e características do próprio sistema. 
No Brasil, em período mais recente, os SME estão sinalizados na Lei n ${ }^{\circ} 5.692$ de 1971 (BRASIL, 1971), lei que regulamentou o $1^{\circ}$ e o $2^{\circ}$ graus no período do regime ditatorial militar que se instaurou em 1964. Através do artigo 71, estabelece que "os Conselhos Estaduais de Educação poderão delegar parte de suas atribuições a Conselhos de Educação que se organizem nos municípios onde haja condições para tanto". Embora essa disposição não estabeleça sistemas municipais de ensino, ela representa uma aprovação inicial da antiga tese de Anísio Teixeira sobre a municipalização do ensino já ensaiada, sem sucesso, em algumas regiões do país. Nesse caso, a consolidação do sistema municipal de ensino será a resultante natural de afirmação política do município.

Um Sistema de Ensino requer um órgão regulador do mesmo, o Conselho Municipal de Educação com funções definidas e regulamentadas em lei.

\section{O Conselho Municipal de Educação}

É imprescindível a existência do CME para que se concretize um Sistema Educacional, pois este órgão é indispensável na constituição de um SME. Bordignon (2009) afirma "É no campo da negociação e mediação entre sociedade e governo, voltados para os interesses coletivos, com visão do todo, que os conselhos encontram sua natureza essencial, seu espaço próprio, sua função precípua" (p. 53-54).

Revendo a caminhada dos Conselhos de Educação no Brasil, apontamos com o autor a criação, em 1911, do Conselho Superior de Educação; em 1925, a criação do Conselho Nacional de Ensino; de 1931 a 1936, o funcionamento do Conselho Nacional de Educação e, com esta denominação de 1936 a 1961, quando da aprovação da primeira LDB do país, a Lei no 4.024/1961 (BRASIL, 1961).

Com esta lei, servindo a seus princípios, de 1962 a 1994, passa a denominar-se Conselho Federal de Educação com 24 conselheiros de livre nomeação pelo Presidente da República. A partir de 1994, período da redemocratização do país, passa a ser novamente denominado de Conselho Nacional de Educação, devendo o mesmo ser representativo da sociedade.

Por sua vez, os Conselhos Estaduais de Educação foram previstos pela Constituição de 1934 e referendados na Constituição de 1946, mas, efetivamente, criados com a LDB (Lei no 4.024 de 1961) (BRASIL, 1961).

Quanto aos Conselhos Municipais de Educação, apesar de terem sido propostos pelos Pioneiros da Educação Nova, especialmente Anísio Teixeira, somente após a 
sinalização de Sistema Municipal de Ensino pela CF/1988 e a institucionalização pela LDB/1996, houve um estímulo à sua criação nos municípios com funções próprias relativas ao SME, sendo que a existência dos mesmos passou a ser objeto privativo das leis orgânicas de Estados e Municípios.

Antes de 1988, os Conselhos tinham a função técnica de planejamento e gestão do ensino, devendo colaborar com o governo na definição de normas, disciplinando matérias e métodos de ensino, elaboração de compêndios escolares, credenciamento e fiscalização de instituições de ensino e outras ações. Eram compostos, inicialmente, por funcionários públicos com cargos de chefia e diretores de escolas. Hoje, o CME assume uma dimensão política, deles devendo participar representantes da sociedade em geral.

A CF/88 (BRASIL, 1988) situou o cidadão na condição de governante e não mais de mero governado. Neste cenário, os movimentos pela democratização da gestão pública requerem, hoje, nova posição dos conselhos: a de responder às aspirações da sociedade e, em nome dela, exercer suas funções. Nesse espírito, os conselhos de educação, assumem uma nova natureza: a de órgãos de Estado e, assim, representam e expressam a vontade nacional, formulando estrategicamente as políticas educacionais.

Nesse caso, os conselhos não mais assumem feição de órgãos de governo quando na sua composição e no exercício de suas funções, expressam, traduzem, legitimam junto à sociedade, a vontade de determinado governo (BORDIGNON, 2009).

$\mathrm{Na}$ ótica democrática os conselhos passam a representar, hoje, uma estratégia privilegiada de democratização das ações do Estado, sendo a representatividade social uma das características do conselho. Quanto às funções, o conselho deve ter competências deliberativas, consultivas, avaliativas e fiscalizadoras sobre as questões pertinentes ao seu sistema de ensino e atuar na mobilização e controle social. Destacam-se como aspectos importantes para analisar as questões de autonomia no funcionamento dos conselhos: as normas de funcionamento, instituto da homologação, a forma de escolha do presidente, a periodicidade de reuniões, as condições materiais e o apoio aos conselheiros para o desempenho de suas funções.

Nesta ótica, analisam-se como os municípios organizam seus Sistemas de Ensino e nele o Conselho Municipal de Educação e o modo como esta organização se reflete nas escolas. 


\section{O Sistemas Municipais de Ensino e o Conselho Municipal de Educação na realidade da Região A. M. Centro}

Este texto, como anunciado anteriormente, vale-se de resultados de pesquisa realizada nos municípios da Região Central do estado do Rio Grande do Sul. A pesquisa utilizou-se do recurso da internet, na qual a troca de informações tem sido uma constante, tendo em vista que o projeto está em andamento. A análise documental através da solicitação e envio de documentos pelos municípios é a base de dados aqui analisada. Para esse estudo, foram selecionados apenas quatro municípios, o que se justifica por terem sido os primeiros a manifestarem interesse em participar desde o início da pesquisa em 2014.

Aqui denominados municípios $\mathrm{A}, \mathrm{B}, \mathrm{C}$ e $\mathrm{D}$, após o convite para participar do projeto, os mesmos foram informados dos objetivos da pesquisa relacionados à construção do SME e o papel do CME neste processo. Logo foram enviados questionários a serem respondidos pelos responsáveis no sentido de cadastrar os municípios, os Secretários Municipais de Educação e Presidentes dos CME.

Os documentos solicitados constaram de: Lei Orgânica do Município, Lei que cria o Sistema Municipal de Ensino, Lei que cria o Conselho Municipal de Educação, Regimento do CME, Plano Municipal de Educação, Lei de Gestão Democrática, Plano de Carreira para Professores, assim como comprovantes de outras atividades realizadas no município como Fóruns de Debates, Seminários e outras atividades pertinentes. O Quadro mostra os documentos enviados pelos municípios.

Quadro. Legislação enviada pelos municípios.

\begin{tabular}{|c|c|c|c|c|c|c|}
\hline Município & $\begin{array}{c}\text { Lei } \\
\text { Orgânica }\end{array}$ & $\begin{array}{l}\text { Lei que } \\
\text { cria o SME }\end{array}$ & $\begin{array}{c}\text { Lei que } \\
\text { cria o CME }\end{array}$ & $\begin{array}{l}\text { Regimento } \\
\text { do CME }\end{array}$ & $\begin{array}{c}\text { Plano } \\
\text { Municipal } \\
\text { de } \\
\text { Educação }\end{array}$ & $\begin{array}{c}\text { Plano de } \\
\text { Carreira e } \\
\text { Remuneração } \\
\text { do Magistério } \\
\text { Municipal }\end{array}$ \\
\hline A & $X\left(s / n^{\circ}\right)$ & $\begin{array}{c}\mathrm{X} \\
\text { Lei } \mathrm{n}^{\circ} \\
572 / 2004\end{array}$ & $\begin{array}{c}\mathrm{X} \\
\text { Lei } \mathrm{n}^{\circ} \\
\text { 10/1993 }\end{array}$ & $x$ & - & - \\
\hline B & - & $\begin{array}{c}X \\
\text { Lei } n^{\circ} \\
2.430 / 2004\end{array}$ & $\begin{array}{c}X \\
\text { Lei } n^{\circ} \\
1.035 / 1991\end{array}$ & $x$ & $x$ & $x$ \\
\hline C & $\begin{array}{c}X \\
\text { Lei } n^{\circ} \\
001 / 2011\end{array}$ & $\begin{array}{c}X \\
\text { Lei no } \\
2.800 / 2007\end{array}$ & $\begin{array}{c}X \\
\text { Lei no } \\
2.014 / 1994\end{array}$ & $x$ & - & - \\
\hline D & $\mathrm{X}\left(\mathrm{s} / \mathrm{n}^{\circ}\right)$ & $\begin{array}{c}X \\
\text { Lei no } \\
\text { 26/2001 }\end{array}$ & $\begin{array}{c}X \\
\text { Lei nº } \\
38 / 1993\end{array}$ & $x$ & - & - \\
\hline
\end{tabular}

Fonte: Elaborado pela autora, 2016. 
Sobre a Lei Orgânica foi possível constatar que, nesta lei, o município A não trata de assuntos educacionais, o que inviabilizou uma análise da educação no contexto da organização municipal. O Município C, através da Lei no $1 / 2011$, no Capítulo II da Educação, da Cultura e do Desporto, assegura o cumprimento dos princípios constitucionais de um piso salarial profissional. O artigo 161 trata da organização do Sistema de Ensino em colaboração com os Sistemas Estadual e Federal de Educação. O artigo 162 trata da criação do Conselho Municipal de Educação, estabelecendo no Parágrafo Único do mesmo artigo que o Sistema fornecerá ao CME, semestralmente, o relatório de execução financeira, o que indica o compromisso do CME com a fiscalização da aplicação dos recursos públicos para a educação.

O município D, através de sua Lei Orgânica, salienta no inciso V do artigo 170 a valorização dos profissionais da educação, garantindo na forma da lei, plano de carreira para o magistério municipal com piso salarial profissional, e ingresso exclusivamente por concurso público de provas e títulos, sem especificidade da legislação sobre esses aspectos.

Com exceção do Município C, as Leis Orgânicas não tratam da constituição do Sistema Municipal de Ensino, o que é explicitado na legislação que trata da organização do Sistema Municipal de Ensino.

Ao analisar-se a legislação sobre o Sistema Municipal de Ensino, nos municípios em pauta, são apresentados os objetivos da educação municipal, as responsabilidades do poder público com a educação, salientando o ensino fundamental, a Educação de Jovens e Adultos (EJA), creche e pré-escola e atendimento especializado aos educandos com necessidades especiais, bem como salientam a organização do Sistema Municipal de Ensino, o qual compreende a Secretaria Municipal de Educação e Cultura, o Conselho Municipal de Educação e as instituições escolares mantidas pelo poder público municipal, bem como as creches mantidas pela iniciativa privada.

O Sistema Municipal de Ensino do município A foi regulamentado em 2004, através da Lei $n^{\circ} 572$. O SME do município $B$ atende os princípios educacionais determinados na CF/1988, bem como os da LDB/1996. Dentre as competências e responsabilidades do município, salienta-se o compromisso de elaborar e manter o Plano Municipal de Educação de duração plurianual, elaborado em conformidade com os princípios dos Planos Nacional e Estadual de Educação, o qual deverá ser previamente aprovado pelo CME e, posteriormente, encaminhado ao poder legislativo municipal. Os artigos 19, 20 e 21 tratam 
dos profissionais da educação, evidenciando o compromisso do poder público com a atualização e aperfeiçoamento dos mesmos, bem como a garantia de um plano de carreira, pagamento do piso salarial profissional, períodos reservados a estudos e planejamento incluídos na carga horária de trabalho e aperfeiçoamento profissional continuado. Os artigos 16 e 17 tratam da gestão democrática, a qual se deverá dar através da participação da comunidade nas decisões escolares em termos administrativo-pedagógicos, incluindo-se a administração de recursos financeiros, bem como nos processos eleitorais para a direção da escola e conselho escolar.

O município C, conforme artigos $1^{\circ}$ e $2^{\circ}$ da Lei no $2.800 / 2007$, indica que o CME tem funções consultiva, deliberativa, propositiva, normativa e de assessoramento ao Secretário Municipal de Educação. Essa lei possui uma seção que trata especificamente do Plano Municipal de Educação. O título IV delibera acerca dos profissionais da educação, garantindo Plano de Carreira, piso salarial da categoria, através de lei municipal específica, ingresso exclusivamente por concurso público de provas e títulos; aperfeiçoamento profissional continuado, dentre outras garantias.

O município D, através da Lei $\mathrm{n}^{\circ} 26 / 2001$ apresenta o SME através do CME como um órgão normativo, consultivo, deliberativo e fiscalizador sobre os assuntos de sua competência, atribuindo ao CME a função de aprovar o Plano Municipal de Educação. O título VI trata da valorização dos profissionais da educação, garantindo aperfeiçoamento profissional, remuneração adequada, progressão funcional e condições de trabalho asseguradas em Plano de Carreira regulamentado em lei específica.

Observa-se que as leis do SME analisadas apresentam os elementos que o constituem adequadamente, bem como tratam do plano de carreira e de remuneração adequada aos profissionais da educação, mas apenas um dos municípios em pauta enviou o plano de carreira e nenhum se referiu ao Piso Nacional de Salários.

Da análise dos Sistemas, importante se faz a organização dos CMEs, salientandose, inicialmente, o Conselho Municipal de Educação do município A, que, através da Lei $n^{\circ}$ 10/1993, especifica as atribuições do CME: oferecer sugestões para elaboração do Plano Municipal de Educação e aplicação dos recursos da educação.

O Conselho Municipal de Educação do Município B, criado pela Lei ${ }^{\circ} 1.035$ de 19/02/1991, trata das comissões para deliberação de assuntos ligados à educação e cultura. 
O Conselho Municipal de Educação do Município C foi instituído, inicialmente, pela Lei $\mathrm{n}^{\circ} 1.752$ de 1989 , alterada pela Lei $\mathrm{n}^{\circ} 42 / 2007$ e, por essa lei, o artigo $9^{\circ}$ trata das Comissões, porém, sem especificidade de número ou funções. O CME deverá exercer funções consultiva, deliberativa, normativa, propositiva e de assessoramento ao Secretário Municipal de Educação.

Os CMEs dos municípios A B e C têm a mesma representação social, devendo cada um dos Conselhos ser composto por nove membros, sendo um terço dos mesmos, professores municipais indicados pela Secretaria Municipal de Educação, um terço de professores indicados pela Associação de Professores Municipais e os demais pela rede estadual de educação. O município $\mathrm{B}$ acrescenta professores da rede particular, o município $C$ acrescenta a estes, funcionários de escola e um representante de pais e o município $\mathrm{D}$, acrescenta professores do ensino superior.

A exceção a esta representação social fica por conta do CME do Município D que, instituído pela Lei $\mathrm{n}^{\circ} 38$ de 1993, conta com 13 membros titulares e 13 suplentes nomeados pelo Prefeito Municipal, assim como não podem fazer parte do CME detentores de cargo de confiança do poder executivo. Essa lei não especifica as funções, bem como as atribuições do CME.

Outro aspecto comum nos quatro municípios é a atribuição de manter intercâmbio com o Conselho Estadual de Educação (CEE), com os demais conselhos municipais e instituições congêneres, bem como exercer as atribuições que são delegadas pelo CEE.

Quanto ao funcionamento, é essencial que o conselho tenha normas claras definindo as competências próprias, seu espaço de poder. Destaca-se, dentre elas, a de elaborar seu próprio regimento nos termos e limites da lei de criação. $\mathrm{O}$ regimento representa a regulamentação das leis municipais que instituem o CME e deverá estabelecer entre outros: competência de caráter consultivo e deliberativo; competências estas, objeto de homologação pelo Executivo; condições e direito a recursos; estrutura de funcionamento; quórum das reuniões; número de sessões; forma de votação; elaboração de pautas e atas.

O Regimento do CME do Município A apresenta os objetivos do CME, salientandose o de assegurar aos grupos representativos da comunidade o direito de participar na definição das diretrizes da educação no município. Apresenta as finalidades e competências, salientando-se, dentre elas a de acompanhar e fiscalizar a construção, a execução e a avaliação do Plano Municipal de Educação a ser elaborado pela SMEC; participar anualmente da previsão orçamentária do município e zelar pelo 
cumprimento da legislação em educação. O capítulo IV referenda a legislação do SME sobre a composição do CME, devendo o mesmo ser constituído de nove membros titulares e seus respectivos suplentes, devendo todos ser professores do ensino público e particular, ativos ou inativos. $\mathrm{O}$ artigo 41 institui três comissões constituídas de quatro membros cada uma, sendo elas: comissão de educação infantil, de ensino fundamental e modalidades, comissão de planejamento de recursos públicos e comissão de avaliação. Este regimento não trata das funções do CME, situação que também não é observada na lei que cria o CME.

O Regimento do CME do município $\mathrm{B}$ estabelece no art. $1^{\circ}$ que o $\mathrm{CME}$ deverá atuar com autonomia, sem subordinação institucional ao poder executivo municipal. $\mathrm{O}$ art. $3^{\circ}$ referenda o que diz a lei sobre os nove membros que compõem o CME.

O Regimento do CME do município C indica os órgãos do conselho: presidência, plenário e comissões. As comissões serão em número de três, sendo duas para atender os níveis de ensino de responsabilidade do município, e uma para estudos de planejamento e normas. As comissões emitirão atos em forma de pareceres, indicações e resoluções.

O Regimento do CME do município $\mathrm{D}$ informa que o CME deverá reunir-se em plenária e sessão ordinária. Poderá constituir comissões, devendo as mesmas dissolver-se após a conclusão dos trabalhos. Assim como na Lei que cria o CME desse município, também no regimento não são especificadas as funções do mesmo.

Considerando os dados acima, dos quatro municípios em pauta, referentes à Lei Orgânica Municipal, à lei que cria o Sistema Municipal de Ensino, à lei que cria o CME e seu respectivo regimento, observa-se que a representação social maior nos CMEs é de representantes do próprio magistério, o que confere um caráter corporativo e não democrático, pois, como diz Saviani (2014, p. 62) a representação dos Conselhos de Educação "não deve ocorrer por representações das entidades sociais que, de alguma forma, se ligam à educação, o que acabaria por lhe conferir um caráter corporativo".

Outro aspecto que chama a atenção é a predominância de nove membros no CME, assim como a subordinação dos mesmos ao Conselho Estadual de Educação, o que indica que os municípios ainda estão na lógica das regulamentações da legislação do período ditatorial militar de 1964, que possibilitou a criação de conselhos municipais com nove membros, mas sem autonomia, o que confere a subordinação ao CEE. Neste caso, nove membros indicam conselhos sem uma significativa representatividade social e não se caracterizam como conselhos, 
uma vez que a pluralidade social e o diálogo interpares ficam muito limitados, considerando as funções atribuídas ao CME, quais sejam: a normativa, a consultiva, a deliberativa e a fiscalizadora.

Um Conselho de Educação, portanto, demanda número de vagas em sua representação social que permita a presença das diferentes categorias sociais situadas no município, e o equilíbrio da diversidade em uma perspectiva democrática. Nesse aspecto, não se cria um Sistema Municipal de Ensino, considerando que sistema de educação é uma "organização intencional dos meios, com vistas a se atingirem os fins educacionais preconizados" (SAVIANI, 2014, p. 44) em determinada esfera governamental, pois se refere ao modo como o próprio fenômeno educativo é (ou deve ser) organizado.

A consolidação do Sistema implica elaboração de planos municipais de educação de duração plurianual, considerando como Saviani (2014) que "[...] as exigências de intencionalidade e coerência implicam que o sistema se organize e opere segundo um plano. Consequentemente há uma estreita relação entre sistema de educação e plano de educação" (p. 81). Seu funcionamento será regulado pelo Plano Municipal de Educação, que se põe como uma exigência para que o SME mantenha permanentemente suas características próprias. "Caso contrário, ele perderá as características próprias dos sistemas, reduzindo-se a uma simples estrutura" (SAVIANI, 2014, p. 81).

Fica, portanto, o compromisso dos municípios de elaborar ou adequar seu PME, em acordo com o que preconiza o PNE/2014.

Os Estados, o Distrito Federal e os Municípios deverão elaborar seus correspondentes planos de educação, ou adequar os planos já aprovados em lei, em consonância com as diretrizes, metas e estratégias previstas neste PNE, no prazo de 1 (um) ano contado da publicação desta Lei (BRASIL, 2014, art. $8^{\circ}$ ).

Efetivamente, nos municípios analisados, conforme determinação do PNE/2014, o Plano Municipal de Educação foi elaborado em 2015, no sentido de adequar os compromissos do município com a organização de Sistema de Ensino, correspondendo, assim, às reais necessidades de uma educação municipal de qualidade social, o que será objeto de outra investigação.

É da tradição do Conselho a eleição do Presidente pelos pares, condição essencial para sua autonomia, o que é observado satisfatoriamente na legislação dos 
municípios estudados. No entanto, comprometedora da organização do Sistema é o exercício das funções do mesmo, pois chamou a atenção, quando do cadastramento de Secretários Municipais de Educação e Presidentes dos Conselhos Municipais de Educação, o exercício dessas funções ser assumido pela mesma pessoa (caso de dois municípios). Esta é uma realidade que descaracteriza os dois órgãos, visto que o exercício da presidência do CME pelo Secretário de Educação, ou por alguém por ele indicado, traz desvantagens para ambos os lados, prejudicando a configuração de um SME na prática, apesar da legislação.

Na perspectiva observada nos municípios, através dos documentos analisados, entende-se que as atribuições a eles conferidas pelo processo de descentralização, oportunizam a ampliação da democracia, consagrando a autonomia municipal no aspecto educacional, o que deve ser corroborado na prática.

O esforço para a concretização do SME é uma tarefa coletiva. É uma situação nova para a educação brasileira, apresentada como solução para o enfrentamento das dificuldades crescentes de funcionamento dos sistemas de educação nos municípios. Com ela, fica garantida a gestão democrática, espaço pelo qual as instituições educativas deverão ser capazes de escolher livremente e de criar suas normas de conduta. A liberdade se condiciona à sua responsabilidade de buscar situações possíveis e necessárias à realidade a que se destina, o que se traduz em políticas de educação municipal através de planos, propostas e projetos educativos.

\section{Considerações finais}

Esse texto tratou da autonomia municipal e da formalização do Sistema Municipal de Ensino, o que, invariavelmente, indica maior democratização e, também, maior racionalização. Abordou a descentralização posta pelo Estado, a qual, se compreendida politicamente, oportuniza importantes mecanismos para se alcançar uma democracia realmente participativa, na qual a comunidade possa ultrapassar a condição histórica de mera presença física nas instituições escolares e na participação nos Conselhos de Educação, desempenhando o seu papel de direito.

Cumpre salientar que o município é a base e o ponto de partida para a construção de uma educação com qualidade social, considerando que a educação é um canal propulsor do desenvolvimento local, regional e nacional. Com a descentralização, tanto política quanto organizacional, afirma-se, portanto, o poder local a ser assumido pela sociedade como consequência do Estado mínimo proposto pelo capital. Assim sendo, a descentralização apresenta dois lados. Por um, dá autonomia e oportuniza uma maior democratização dos espaços. Por sua vez, também se configura como uma estratégia do capital para maior controle social. Nesse caso, 
[...] pode-se afirmar que a descentralização tem sido uma das estratégias privilegiadas, por meio da qual se procura imprimir a "nova racionalidade" aos respectivos sistemas de ensino [...] diferentes concepções ou significados são atribuídos à descentralização, sendo possível classificá-la como: a) desconcentração, entendida como delegação de responsabilidades administrativas às esferas inferiores dentro da instância governamental; b) transferência de responsabilidades a organizações e ou entidades que atuam fora do governo, mas ficando controladas diretamente por este [...] (SOUZA, 2010, p. 99, grifos do autor).

Tais referências implicam a necessidade dos responsáveis pela formalização de Sistemas Municipais de Ensino: Secretaria Municipal de Educação, Conselho Municipal de Educação e rede escolar municipal compreenderem criticamente o processo de descentralização, visto que, se por um lado abre novas e inéditas possibilidades para a efetivação de Sistema de Ensino, que tenha na comunidade uma parceira nos assuntos de seus interesses e, naturalmente, para a prática da educação em uma perspectiva emancipadora, por sua vez, também pode colocarse como instrumento de controle social e limitação da autonomia municipal.

Para tanto, é preciso ter presente o modelo de Estado e o papel da educação nesse contexto. O objetivo norteador deve ser a consciência da necessidade da formação de cidadãos para atuar em sociedades complexas, como as que se estruturam, hoje, frente ao mundo globalizado e de extrema complexidade tecnológica, cujas exigências de conhecimento e de compreensão da realidade requerem a imediata superação de modelos educacionais pobres de conhecimentos, distanciados de uma leitura crítica de mundo, reprodutivistas das desigualdades sociais e despreparados para enfrentar os desafios que a realidade social, política, econômica e cultural impõem à sociedade. 


\section{The Municipal System of education in analysis: advances and challenges}

\section{Abstract}

Seeking to verify the existence of Municipal System of Education, legally instituted in towns of Central Region of RS, this text uses a documental and theoretical-bibliographic search, having as reference the purchased data through the project of search "Municipal System of Education and Municipal Council of Education: reality and viabilities", since 2014. Seek to contribute to the advance in relation to the goals and the engagements of PNE/2014/2024, identifying weaknesses and possibilities. For that, it treats of organization of Municipal System of Education that, in cooperation with the Municipal Council of Education and the school network, formalizes the Municipal System of Education. The results indicate that the existence of legislation that formalizes a Municipal System of Education is not a guarantee of its operationalization in practice.

Keywords: Municipal System of Education. Municipal legislation. Challenges.

\section{Sistema Municipal de Educación en revisión: avances y desafios}

\section{Resumen}

En la búsqueda por comprobar si hay Sistema Municipal de Educación establecida de forma legal en los municipios de la Región Central de la provincia del Rio Grande del Sur/RS, este texto se basa en la investigación teórica bibliográfica y documental, con referencia a los datos adquiridos a partir del proyecto de investigación "Sistema Municipal de Educación y Consejo Municipal de Educación: la realidad y la viabilidad”, desde el año 2014. Busca contribuir con el progreso hacia los objetivos y compromisos del Plan Nacional de Educación (PNE/2014/2024), identificando las debilidades y posibilidades. Aborda la organización del Sistema Municipal de Educación y, en esto, la importancia de la Secretaría Municipal de Educación, junto al Consejo Municipal de Educación y la red de escuelas, que formalizan el Sistema Municipal de Educación. Los resultados indican que la existencia de una legislación y la formalización de un Sistema Municipal de Educación no es garantía de su funcionamiento en la práctica.

Palabras clave: Sistema Municipal de Educación. Legislación municipal. Desafios. 


\section{Referências}

AROSA, D. V. S. Sistema Municipal de Ensino e construção do discurso oficial sobre avaliação da aprendizagem. In: SARMENTO, D. C. (Org.). Sistemas de Educação no Brasil: políticas, autonomia e cooperação. Juiz de Fora: UFJF, 2010, p. 75-101.

AZANHA, J. M. P. Uma ideia sobre a municipalização do ensino. Estudos Avançados, v. 5, n. 12, p. 61-68, 1991. doi: https://dx.doi.org/10.1590/S0103-40141991000200005.

BORDIGNON, G. Gestão da Educação no município: sistema, conselho e plano. São Paulo: Instituto Paulo Freire, 2009.

BRASIL. Constituição (1988). Constituição da República Federativa do Brasil. Brasília, DF: Senado, 1988. Disponível em: <http://www.planalto. gov.br/ccivil_03/constituicao/constituicao.htm>. Acesso em: Acesso em: 13 dez. 2016.

Emenda Constitucional No 14, de 12 de setembro de 1996. Modifica os arts. 34, 208, 211 e 212 da Constituição Federal e dá nova redação ao art. 60 do Ato das Disposições constitucionais Transitórias. Diário Oficial da União da República Federativa do Brasil, Brasília, DF, 13 set. 1996a. Disponível em: http://www.planalto.gov.br/ccivil_03/constituicao/emendas/ emc/emc14.htm. Acesso em: 16/02/2018.

. Lei No 4.024, de 20 de dezembro de 1961. Fixa as Diretrizes e Bases da Educação Nacional. Disponível em: <http://www2.camara.leg.br/legin/fed/ lei/1960-1969/lei-4024-20-dezembro-1961-353722-publicacaooriginal-1-pl. html>. Acesso em: 22 nov. 2016.

. Lei $\mathrm{N}^{\circ} 5.692$ de 11 de agosto de 1971 (Revogada pela Lei № 9.394, de 20-12-1996). Fixa Diretrizes e Bases para o Ensino de $1^{\circ}$ e $2^{\circ}$ Graus, $e$ dá outras Providências. Disponível em: <http://www.camara.gov.br/sileg/ integras/136683.pdf>. Acesso em: 12 abr. 2016.

. Lei $\mathrm{N}^{0}$ 9.394, de 20 de dezembro de 1996. Estabelece as diretrizes e bases da educação nacional. Diário Oficial da União da República Federativa do Brasil, Brasília, DF, 23 dez. 1996b. Disponível em: <http://www.planalto. gov.br/ccivil_03/leis/19394.htm>. Acesso em: 20 jun. 2016. 
BRASIL. Lei No 11.494, de 20 de junho de 2007. Regulamenta o Fundo de Manutenção e Desenvolvimento da Educação Básica e de Valorização dos Profissionais da Educação - FUNDEB, de que trata o art. 60 do Ato das Disposições Constitucionais Transitórias; altera a Lei n ${ }^{\circ} 10.195$, de 14 de fevereiro de 2001; revoga dispositivos das Leis $\mathrm{n}^{\text {os }} 9.424$, de 24 de dezembro de 1996, 10.880, de 9 de junho de 2004, e 10.845, de 5 de março de 2004; e dá outras providências. Diário Oficial da União da República Federativa do Brasil, Brasília, DF, 21 jun. 2007. Disponível em: <http://www.planalto.gov. br/ccivil_03/_ato2007-2010/2007/lei/111494.htm>. Acesso em: 20 jun. 2016.

. Lei $\mathrm{N}^{\mathrm{o}} 13.005$, de 25 de junho de 2014. Aprova o Plano Nacional de Educação - PNE e dá outras providências. Diário Oficial da União da República Federativa do Brasil, Brasília, DF, 26 jun. 2014. Disponível em: $<$ http://www.planalto.gov.br/CCIVIL_03/_Ato2011-2014/2014/Lei/L13005. htm>. Acesso em: 15 jul. 2015.

. Ministério da Educação. Secretaria de Educação Básica. Pradime: programa de apoio aos dirigentes municipais de educação. Brasília, DF: MEC/ SEB, 2006. (Caderno de Textos, v. 3.).

GÓMEZ, J. M. Política e democracia em tempos de globalização. Petrópolis, RJ: Vozes; Buenos Aires: CLACSO; Rio de Janeiro: Laboratório de Políticas Públicas, 2000.

MONLEVADE, J. Educação pública no Brasil: contos e descontos. Brasília, DF: Ideia, 1997.

MOTA, A.B.R. A história da municipalização do ensino no Brasil. In: JORNADA DO HISTEDBR, 7., 2007, Campo Grande. Anais... Campo Grande: Unicamp, não paginado. Disponível em: $<$ http://www.histedbr. fae.unicamp.br/acer_histedbr/jornada/jornada $7 / G T 2 \% 20 \mathrm{PDF} / \mathrm{A} \% 20$ HIST\%D3RIA\%2>. Acesso em: 20 fev. 2016.

PEREIRA, S. M. Sistema Municipal de Ensino e Conselho Municipal de Educação: realidade e viabilidades. Santa Maria, RS: UFSM, 2014. Projeto de pesquisa.

SANDER. B. Sistemas na educação brasileira: solução ou falácia? São Paulo: Saraiva, 1985.

SANTOS, H. O. Ideário Pedagógico Municipalista de Anísio Teixeira. Cadernos de Pesquisa, n. 110, p. 105-124, 2000. doi: http://dx.doi.org/10.1590/S0100-15742000000200004. 
SAVIANI, D. Educação brasileira: estrutura e sistema. 5. ed. São Paulo: Saraiva, 1983.

. Sistema Nacional de Educação e Plano Nacional de Educação.

Campinas: Autores Associados, 2014.

SOUZA, A. L. L. Estado e educação pública: tendências administrativas e de gestão. In: OLIVEIRA, D. A; ROSAR, M. F. F. (Org.) Política e gestão da escola. 3. ed. Belo Horizonte: Autêntica, 2010. p. 91-105.

TAVARES, O. Prioridade número um para a educação: entrevista de Anísio Teixeira ao Diário de Notícias da Bahia, 1952. Rio de Janeiro: Ministério da Educação e Saúde, 1952. (Serviço de Documentação).

\section{Informações dos autores}

Sueli Menezes Pereira: Doutora em Educação. Professora do Programa de Pós-Graduação em Educação da Universidade Federal de Santa Maria/RS. Contato: sueli.ufsm@gmail.com 